\title{
BMJ Open Factors associated with maternity waiting home use among women in Jimma Zone, Ethiopia: a multilevel cross-sectional analysis
}

\author{
Jaameeta Kurji, ${ }^{\oplus 1}$ Lakew Abebe Gebretsadik, ${ }^{2}$ Muluemebet Abera Wordofa, ${ }^{3}$ \\ Morankar Sudhakar, ${ }^{2}$ Yisalemush Asefa, ${ }^{4}$ Getachew Kiros, ${ }^{2}$ Abebe Mamo, ${ }^{2}$ \\ Nicole Bergen, ${ }^{5}$ Shifera Asfaw, ${ }^{2}$ Kunuz Haji Bedru, ${ }^{6}$ Gebeyehu Bulcha, ${ }^{6}$ \\ Ronald Labonte, ${ }^{1}$ Monica Taljaard, ${ }^{7}$ Manisha Kulkarni ${ }^{1}$
}

To cite: Kurji J, Gebretsadik LA, Wordofa MA, et al. Factors associated with maternity waiting home use among women in Jimma Zone, Ethiopia: a multilevel crosssectional analysis. BMJ Open 2019;9:e028210. doi:10.1136/ bmjopen-2018-028210

- Prepublication history for this paper is available online. To view these files, please visit the journal online (http://dx.doi org/10.1136/bmjopen-2018028210).

Received 27 November 2018 Revised 02 August 2019 Accepted 05 August 2019
Check for updates

(C) Author(s) (or their employer(s)) 2019. Re-use permitted under CC BY-NC. No commercial re-use. See rights and permissions. Published by BMJ.

For numbered affiliations see end of article.

Correspondence to

Jaameeta Kurji;

jkurj022@uottawa.ca

\section{ABSTRACT}

Objective To identify individual-, household- and community-level factors associated with maternity waiting home (MWH) use in Ethiopia.

Design Cross-sectional analysis of baseline household survey data from an ongoing cluster-randomised controlled trial using multilevel analyses.

Setting Twenty-four rural primary care facility catchment areas in Jimma Zone, Ethiopia.

Participants 3784 women who had a pregnancy outcome (live birth, stillbirth, spontaneous/induced abortion) 12 months prior to September 2016.

Outcome measure The primary outcome was selfreported MWH use for any pregnancy; hypothesised factors associated with MWH use included woman's education, woman's occupation, household wealth, involvement in health-related decision-making, companion support, travel time to health facility and community-levels of institutional births.

Results Overall, $7 \%$ of women reported past MWH use. Housewives (OR: $1.74,95 \% \mathrm{Cl} 1.20$ to 2.52 ), women with companions for facility visits (OR: $2.15,95 \% \mathrm{Cl} 1.44$ to 3.23 ), wealthier households (fourth vs first quintile OR: $3.20,95 \% \mathrm{Cl} 1.93$ to 5.33 ) and those with no health facility nearby or living $>30$ min from a health facility (OR: $2.37,95 \% \mathrm{Cl} 1.80$ to 3.13 ) had significantly higher odds of MWH use. Education, decision-making autonomy and community-level institutional births were not significantly associated with MWH use.

Conclusions Utilisation inequities exist; women with less wealth and companion support experienced more difficulties in accessing MWHs. Short duration of stay and failure to consider MWH as part of birth preparedness planning suggests local referral and promotion practices need investigation to ensure that women who would benefit the most are linked to MWH services.

\section{INTRODUCTION}

Maternal mortality has declined significantly in Ethiopia over the last two decades. It was estimated to be 720 deaths per 100000 live births in $2005^{1}$ but dropped to 412 deaths
Strengths and limitations of this study

- A notable strength of the study was the simultaneous consideration of individual-level and contextual-level factors associated with actual maternity waiting home (MWH) use using a relatively large, community-based data set; several studies conducted on MWH use have focused on the influence of service quality.

- We used statistical analyses which explicitly accounted for the clustered nature of our data through generalised linear mixed models.

- The cross-sectional nature of the analysis limits our ability to make any conclusions about the causal relationship between hypothesised influential factors and MWH use.

per 100000 live births by $2016 .^{2}$ Making motherhood safer is a priority for the Ethiopian government and various efforts, such as establishing the health extension programme (HEP), ${ }^{3}$ have been directed to reduce maternal mortality. Also among these has been the scale-up of maternity waiting homes $(\mathrm{MWHs})^{4}$ which were initially concentrated at the hospital level ${ }^{5}$ but have more recently been implemented at lower-level health centres. MWHs are temporary residential spaces located within or close to health facilities offering skilled obstetrical care. They provide an opportunity for pregnant women who experience geographical barriers to be near a health facility a few weeks before birth. MWHs have also been recommended for housing pregnant women who may be at risk of delivery complications so that they can be closely monitored by health workers. ${ }^{6}$

Utilisation levels of MWHs globally have generally been reported to be low with their conditions often regarded as unsatisfactory. ${ }^{78}$ 
Formative work in Zambia revealed that perceptions about discomfort experienced at MWH because of overcrowding, lack of beds and water shortages can influence use $^{9}$; in Malawi, satisfaction with MWHs was associated with decent toilets and showers, accommodation for companions, adequate sleeping areas and availability of private storage spaces among other amenities. ${ }^{10}$ In Kenya, women were unhappy with health worker attitudes and felt that staff should check on them more often during their stay at the MWH. ${ }^{11}$ Ethiopian users wished for better quality meals and in many cases had to rely on family for food supplies. ${ }^{5}$

Although, service quality plays an important role in MWH use, other factors may do so and need to be considered to optimise utilisation. A cross-sectional, facility based survey in Tanzania found that women's socioeconomic status and distance from health facility was associated with having stayed at an MWH prior to delivery. ${ }^{12}$ In Ethiopia, intended MWH use was reported to be associated with history of obstetrical complications and not perceiving barriers to MWH use. ${ }^{13}$ A Zambian household survey reported marital status and distance being statistically associated with being an MWH user. ${ }^{14}$ As part of the continuum of maternal healthcare services, it is also conceivable that factors shaping the usage of other services may also influence MWH use, as the service largely functions to link women to obstetrical care. Women's education level, ${ }^{15}{ }^{16}$ household wealth, ${ }^{15}{ }^{17}$ decision-making dynamics ${ }^{15}$ social norms around service use ${ }^{18}$ and travel time to care facility ${ }^{19}$ have been reported to influence use of antenatal, obstetrical or postnatal care services in Ethiopia and in a number of countries in sub-Saharan Africa.

Consideration of individual and contextual factors when examining women's access to health services is key. Service use, a proxy for access to care, is influenced by availability of quality services but also by women's ability to obtain these services. ${ }^{20}$ Women's ability in turn is shaped by household and community level factors. ${ }^{21}$ To have equitable, gender-responsive health systems that cater to the specific needs of women facing a multitude of structural barriers, requires a holistic understanding of the factors shaping use. ${ }^{22}$

The primary objective of this analysis, therefore, was to identify factors associated with maternity waiting home use at the individual, household and community levels among women in Jimma Zone, Ethiopia. A secondary objective was to describe community awareness of MWH services and user experiences in the area.

\section{METHODS}

\section{Study setting}

Data used in this analysis were collected from three districts in Jimma Zone located in the southern part of Ethiopia. Gomma, Seka Chekorsa and Kersa districts are primarily rural and had populations ranging from 180000 to 270000 in $2016 .{ }^{23}$ The districts were purposefully selected from the 21 comprising Jimma Zone as they had the largest available population sizes compared with other districts, had poorly functioning MWHs according to Jimma Zone Health Office (JZHO) data, and did not have ongoing maternal health interventions such as other research or development projects or maternal health campaigns to minimise potential co-interventions and to facilitate a more even distribution of interventions as requested by our JZHO partners.

Ethiopia's three-tiered healthcare system consists of a district hospital and primary healthcare units (PHCUs) made up of a health centre and community-based health posts - at the bottom. Levels 2 and 3 include general and specialised hospitals respectively. ${ }^{3}$ In partnership with the District Health Offices, the JZHO oversees service delivery at the 26 health centres present in the study area.

All health centres have either temporary spaces or permanent, standalone structures designated to provide MWH services. According to the national guidelines, women who live far away from health centres, are inaccessible by ambulance, are 38 weeks or more pregnant and/or are at risk of experiencing obstetrical complications during delivery are eligible for MWH referral. ${ }^{4} \mathrm{MWH}$ s are typically expected to consist of two rooms each accommodating six women and to have a suitable space equipped with utensils for women to prepare food or offer meals to women who cannot afford to provide for themselves. MWHs should have access to clean water, latrines and a power source. ${ }^{4}$ Exit surveys conducted nationally in 2016 revealed only $50 \%$ of rural MWHs had water available, $65 \%$ had an electricity supply and $73 \%$ had latrines although most were shared with other patients. ${ }^{24}$ As part of the country's strategy to reduce maternal mortality, the MWH policy was drafted in 2013 to standardise the service provision of this joint community-health system, fee-free initiative. MWH operations are mainly sustained through community cash or crop contributions while management is handled by health centre staff. Reliance on community contributions may result in some variation between the districts in the quality and availability of MWH services.

Health extension workers (HEWs), based in health posts, link communities to the health system by tracking pregnant women in their catchment areas and referring them for services. ${ }^{25}$ Additionally, HEWs provide community-based primary healthcare as prescribed in the 16 modules of the HEP; HEWs offer education and counselling, conduct physical exams of pregnant women, make referrals to health facilities among other antenatal services at the health post. They also conduct postnatal home visits to check-up on mothers and babies. ${ }^{326}$

\section{Background about the trial and baseline survey}

The data source for this analysis was a baseline survey conducted prior to intervention roll-out in an ongoing cluster-randomised controlled trial aiming to evaluate the effectiveness of two safe motherhood interventions in improving institutional births: (i) functional $\mathrm{MWHs}$ and (ii) local leader education (ClinicalTrials.gov Identifier: NCT03299491). The MWH component focuses on improving amenities and services available at the MWHs 
to improve uptake. The education component targets village and religious leaders and uses culturally sensitive trainings to highlight the importance of safe motherhood and delivering at health facilities; materials were developed to address the barriers to maternal care identified in the Three Delays framework. ${ }^{27}$

The survey targeted 3840 women (24 clusters with 160 each); the sample size was determined by the primary outcome (institutional delivery) of the trial. ${ }^{28}$ This sample size achieves $80 \%$ power to detect an absolute difference in the proportions of institutional delivery of 0.17 assuming a control arm proportion of 0.4 and using a two-sided alpha of 0.025 to account for two pairwise comparisons. Women living within catchment areas of trial PHCUs who had a pregnancy outcome (live birth, stillbirth, miscarriage or abortion) up to 1 year prior to the survey were eligible. A two-stage sampling strategy was employed. First, 24 PHCUs were randomly selected for the trial. Then, 160 women per PHCU were randomly selected from community-based lists of pregnant women generated as part of health post records. HEWs and the Women's Health Development Army (community-based administration) periodically update these lists.

During household interviews conducted between October 2016 and January 2017, data were collected on sociodemographic characteristics, reproductive history, utilisation of various maternal healthcare services including MWHs, decision-making and social support. Structured questionnaires were mostly developed by adapting questions from the Demographic and Health Surveys. Questionnaires were piloted in Mana district, located adjacent to the study districts, and refined based on participant and interviewer feedback on question and response acceptability as well as interview duration. Adaptations primarily involved providing response options suited to the study area. Questionnaires were programmed in Open Data Kit on tablet computers in English, Afaan Oromo and Amharic for data collection. Translations were verified by research team members fluent in these languages. Trained research assistants conducted face-to-face interviews with women in a quiet, private space at the women's homes; interviews took about 1 hour to complete. Husbands were also interviewed using a shorter version of the women's questionnaire that included information on travel times to health facilities. Data were available for 3784 (98.5\%) women recruited; due to lack of time, illness or the need for husband permission, $56(1 \%)$ women refused to take part in the study.

\section{Variables of interest}

Definitions of variables used in this analysis are presented in table 1 . The primary outcome was self-reported MWH use for any pregnancy. Candidate explanatory variables, identified from the literature, and hypothesised to be associated with MWH use at the individual level were women's education and women's occupation; at the household level, household wealth, women's involvement in healthcare-related decision-making, having a companion to accompany women for health facility visits during pregnancy and travel time from home to nearest health centre were considered.

The household wealth variable was created using principal components analysis of items listed in table 1; items were selected to minimise clustering and truncation which compromise reliability. ${ }^{29}$ Briefly, socioeconomic 'scores' were generated for each household, which were then grouped into quintiles; the lowest quintile corresponded to the poorest households and the fifth quintile corresponding to the least poor households. ${ }^{29}$

Several dimensions of social support including financial or in-kind assistance, emotional support and practical support were assessed in the survey. Companion support was the dimension most relevant for maternity waiting home use.

To allow us to explore the potential effect of community birthing norms on MWH use, the percentage of women delivering at a health facility was calculated for each PHCU catchment area and the PHCU-level means compared between MWH users versus non-users; the use of similar proxy variables for social norms have been used to explore contextual effects on utilisation of maternal healthcare services in studies conducted in Ethiopia ${ }^{18}$ and Africa. ${ }^{30}$

\section{Data analysis}

Characteristics of MWH users and non-users were described using frequencies and proportions or means and SD. $\mathrm{X}^{2}$ tests for categorical variables, and t-tests for continuous variables adjusted for clustering were performed using methods of Donner \& Klar. ${ }^{31}$ Frequencies and proportions of community awareness of MWHs, reasons for use among users and services available to users were also reported.

To identify variables associated with $\mathrm{MWH}$ use, multivariable generalised linear mixed effects regression was used. All candidate explanatory variables (education, occupation, household wealth, decision-making involvement, companion support, travel time and community birthing norms) were entered into the model. District of residence reported by the woman was included as a covariate to adjust for any district-level differences. A logit link function with a binomial distribution was used. To account for clustering, a random intercept was added for the PHCU. P values less than 0.05 were considered to be statistically significant. Analysis was conducted in STATA V.13.

\section{Patient and public involvement}

Patients/public were not involved in the design or implementation of this research. Results will be disseminated to policy-makers and local-level service implementers.

\section{RESULTS}

\section{Characteristics of MWH users and non-users}

Overall, 256 (7\%) of women had ever used MWH services. Women's mean age 28 years (SD 6 years) and the majority $(78 \%)$ had more than one child. There was a statistically significant difference in the proportions of women who reported being able to reach a health centre or hospital 
Table 1 Definitions of variables used to explore factors associated with women's use of MWHs in three districts in Jimma Zone, Ethiopia (2016-2017)

\begin{tabular}{|c|c|}
\hline Variable & Definition \\
\hline \multicolumn{2}{|l|}{ Outcome variable } \\
\hline Maternity waiting home use & $\begin{array}{l}\text { Binary variable indicating stay at an } \mathrm{MWH} \text { reported by women for any previous pregnancy } \\
\text { (yes or no). }\end{array}$ \\
\hline
\end{tabular}

\section{Independent variables}

Education

Occupation

Household wealth

\begin{tabular}{|c|c|}
\hline Healthcare decision-making & $\begin{array}{l}\text { Women were asked who usually makes decisions about (i) their own health and (ii) their } \\
\text { children's health. Women indicated whether they made decisions on their own, jointly } \\
\text { with someone else or were not involved. Responses for both questions were collapsed } \\
\text { into three categories: never involved, sometimes involved or always involved. 'Never } \\
\text { involved' included women who described someone other than themselves being involved } \\
\text { in healthcare decision-making for both themselves and their children. 'Sometimes involved' } \\
\text { included women who described that they were either involved in healthcare decisions } \\
\text { about their own health or decisions about their children's health. 'Always involved' included } \\
\text { women who described being involved in both healthcare decisions about their own health } \\
\text { and that of their children. }\end{array}$ \\
\hline $\begin{array}{l}\text { Companion support for facility } \\
\text { visits }^{\star}\end{array}$ & $\begin{array}{l}\text { As part of an assessment of social support available to women during pregnancy, women } \\
\text { were asked if they had someone to accompany them to health facility visits (yes or no). This } \\
\text { dimension of support has been termed companion support. }\end{array}$ \\
\hline $\begin{array}{l}\text { Travel time to obstetric care } \\
\text { facility }\end{array}$ & $\begin{array}{l}\text { Women's estimates of the time required to reach the nearest health facility able to provide } \\
\text { obstetrical care were classified into two categories: (i) none nearby (ie }>30 \mathrm{~min} \text { ) and } \\
\text { (ii) } \leq 30 \text { min away. Women who listed a health post as their nearest health facility were } \\
\text { classified under'none' as health posts do not routinely provide delivery services. For the } \\
5 \% \text { of women who were unable to estimate travel, available husband responses were used } \\
\text { to minimise missing data. }\end{array}$ \\
\hline Community birthing norms & $\begin{array}{l}\text { Percentage of women in a PHCU cluster that reported having ever given birth at a health } \\
\text { facility. }\end{array}$ \\
\hline \multicolumn{2}{|l|}{ Covariates and design variables } \\
\hline District & District of residence (Gomma, Seka Chekorsa or Kersa) reported by women. \\
\hline Primary healthcare unit & $\begin{array}{l}\text { Health system administrative level comprising a health centre and satellite health posts that } \\
\text { functioned as cluster-level sampling unit in the trial. }\end{array}$ \\
\hline
\end{tabular}

*Several dimensions of social support including financial or in-kind assistance, emotional support and practical support were assessed in the survey. Companion support was the dimension most relevant for maternity waiting home use.

$\mathrm{MWH}$, maternity waiting home; PHCU, primary healthcare unit.

providing obstetrical services within $30 \mathrm{~min}$ among users (49\%) versus non-users $(72 \%)$ (table 2 ).

Although not statistically significant, a larger proportion of MWH users reported both primary (45\% vs 39\% among non-users) and secondary or higher education levels $(7 \%$ vs $5 \%$ among non-users) and a slightly larger proportion tended to be housewives ( $86 \%$ vs $77 \%$ ). A greater fraction of the users than non-users came from wealthier households (91\% vs $79 \%)$ and reported having companion support for facility visits ( $88 \%$ vs $77 \%$ ) (table 2$)$.
The proportion of women who described themselves as always being involved in healthcare-related decision-making was lower among MWH users $(6 \%)$ than non-users $(9 \%)$ (table 2).

\section{Community exposure to MWHs and user experiences}

Overall, 2679 (71\%) women interviewed had heard about MWH services in their community but a smaller proportion knew of someone who had used one $(36 \%)$ or had actually visited someone at an MWH (28\%). Most women could 
Table 2 Individual-, household- and community level characteristics of MWH users compared with non-users in three districts in Jimma Zone, Ethiopia (2016-2017)

$\begin{array}{llll}\begin{array}{l}\text { MWH users } \\ (\mathrm{n}=256)\end{array} & \begin{array}{l}\text { MWH non-users } \\ (\mathrm{n}=3528)\end{array} & \text { Overall, \% } & \text { P value }\end{array}$

\begin{tabular}{|c|c|c|c|c|}
\hline \multicolumn{5}{|l|}{ Individual level } \\
\hline \multicolumn{5}{|l|}{ Age (years) } \\
\hline$<20$ & $18(7.0)$ & $230(6.5)$ & $48(6.6)$ & 0.687 \\
\hline $20-30$ & $177(69.1)$ & $2180(61.8)$ & 2357 (62.3) & \\
\hline$>30$ & $59(23.1)$ & 1008 (28.6) & 1067 (28.2) & \\
\hline Missing & $2(<1)$ & $110(3.1)$ & $112(2.9)$ & \\
\hline \multicolumn{5}{|l|}{ Education level } \\
\hline None & $123(48.1)$ & 1978 (56.0) & 2101 (55.5) & 0.577 \\
\hline Primary school & $116(45.3)$ & $1368(38.8)$ & $1484(39.2)$ & \\
\hline$\geq$ Secondary school & $17(6.6)$ & $182(5.2)$ & $199(5.3)$ & \\
\hline \multicolumn{5}{|l|}{ Occupation } \\
\hline Housewife & 219 (85.6) & 2715 (77.0) & $2934(77.5)$ & 0.186 \\
\hline Farmer/trader/other & $37(14.4)$ & $813(23.0)$ & $850(22.5)$ & \\
\hline \multicolumn{5}{|l|}{ Parity } \\
\hline one child & 74 (28.9) & 753 (21.3) & 827 (21.9) & 0.240 \\
\hline$>1$ child & $182(71.1)$ & 2775 (78.7) & 2957 (78.1) & \\
\hline \multicolumn{5}{|l|}{ Household level } \\
\hline \multicolumn{5}{|l|}{ Household wealth } \\
\hline Poorest quintile & $23(9.0)$ & $734(20.8)$ & 757 (20.0) & 0.195 \\
\hline Second quintile & $40(15.6)$ & $718(20.4)$ & $758(20.0)$ & \\
\hline Third quintile & $52(20.3)$ & 703 (19.9) & 755 (19.9) & \\
\hline Fourth quintile & $71(27.7)$ & $686(19.5)$ & 757 (20.0) & \\
\hline Least poor quintile & $70(27.4)$ & $686(19.5)$ & $756(20.0)$ & \\
\hline Missing & 0 & $1(<1)$ & $1(<1)$ & \\
\hline \multicolumn{5}{|c|}{ Healthcare decision involvement } \\
\hline Never & $57(22.3)$ & $768(21.8)$ & $825(21.8)$ & 0.703 \\
\hline Sometimes & $185(72.2)$ & $2435(69.0)$ & 2620 (69.2) & \\
\hline Always & $14(5.5)$ & $324(9.2)$ & $338(8.9)$ & \\
\hline Missing & 0 & $1(<1)$ & $1(<1)$ & \\
\hline \multicolumn{5}{|c|}{ Social support during pregnancy } \\
\hline Practical help & $226(88.3)$ & $3202(90.8)$ & $3428(90.6)$ & 0.586 \\
\hline Facility visit companion & $225(87.9)$ & $2723(77.2)$ & 2948 (77.9) & 0.097 \\
\hline \multicolumn{5}{|c|}{ Travel time to obstetrical care facility } \\
\hline$\leq 30$ min away & $126(49.2)$ & $2541(72.0)$ & 2667 (70.5) & 0.001 \\
\hline$>30$ min (none nearby) & $130(50.8)$ & $987(28.0)$ & $1117(29.5)$ & \\
\hline Community level & $(\text { mean \% (SD) })^{*}$ & $($ mean \% (SD))† & (mean \% & \\
\hline Community birthing norms & $34.0(12.0)$ & $31.7(11.2)$ & $31.8(11.2)$ & 0.809 \\
\hline
\end{tabular}

${ }^{*}$ The PHCU-level percentage of women who reported ever giving birth at a health facility averaged across all PHCUs where MWH users live. †The PHCU-level percentage of women who reported ever giving birth at a health facility averaged across all PHCUs where non users live $p$ values $<0.05$ considered statistically significant. $\mathrm{MWH}$, maternity waiting home. 
Table 3 Reasons for MWH stay, and services received among women users in three districts in Jimma Zone, Ethiopia $(2016-2017)(n=256)$

\begin{tabular}{lcc}
\hline & Frequency & \% users* \\
\hline Reasons for use & 191 & 74.6 \\
\hline HEW referral & 37 & 14.5 \\
\hline Complications expected & 34 & 13.3 \\
\hline Prior use of MWH & 31 & 12.1 \\
\hline Live far from health facility & 17 & 6.6 \\
\hline To ensure facility delivery & 14 & 5.5 \\
\hline Needed rest & 18 & 7.0 \\
\hline Other reasons & & \\
\hline Services available during stay & 253 & 98.8 \\
\hline Bedding & 184 & 71.9 \\
\hline Meals & 62 & 24.2 \\
\hline Coffee & 203 & 79.3 \\
\hline Latrines & 82 & 32.0 \\
\hline Bathing facilities & 141 & 55.1 \\
\hline Clean water & 114 & 44.5 \\
\hline Electricity/lighting & 195 & 76.2 \\
\hline Midwife checks & & \\
\hline
\end{tabular}

${ }^{*}$ Multiple responses possible therefore percentages do not sum to 100 .

$\mathrm{HEW}$, health extension worker; $\mathrm{MWH}$, maternity waiting home.

describe at least one benefit of MWH use and these typically included easy access to skilled birth attendants (57\%) and an opportunity to rest (43\%). Only $16 \%$ of women recognised not having to organise emergency transport during labour as a benefit of MWH stay. Very few women who did report planning for their delivery listed getting an MWH referral $(\mathrm{n}=34,1.3 \%)$ as a component of birth preparedness planning (results not shown in tables).

HEWs were important mediators of access to MWHs as almost $75 \%$ of users had obtained a referral from HEWs (table 3). About $15 \%$ of users stayed at MWHs because they anticipated delivery complications and wanted to be close to health workers (table 3). Only $12 \%$ of MWH users cited large distances between home and health centre as the reason for stay (table 3 ).

Close to $60 \%$ of users were admitted just 24 hours prior to delivery; $25 \%$ of users reported staying at the MWH less than 1 week ( 1 to 7 days) prior to delivery while $16 \%$ were accommodated at the MWH for more than 1 week before giving birth (results not shown in tables). Most users were provided with some simple bedding and about $72 \%$ were given some food during their stay. However, clean water, lighting, bathing facilities and coffee ceremony (an important cultural routine in households that creates a home-like environment at MWHs) services were not widely available (table 3). Just over a quarter of the women said family visits were permitted during their stay (results not shown in tables).
Multivariable regression analysis of factors associated with maternity waiting home use

One individual-level factor and three household-level factors resulted in statistically significant higher odds of ever having used an MWH. At the individual level, women's occupation was associated with MWH use. Housewives had higher odds of MWH use than women who had an occupation outside the home (OR: 1.74, $95 \%$ CI 1.20 to 2.52 ) (table 4 ). At the household level, companion support, travel time to health facilities and household wealth were associated with MWH use.

Women who described having companions to accompany them for health facility visits when they were pregnant or for delivery had twice the odds of having used an MWH than women who did not have this form of social support (OR: 2.15, 95\% CI 1.44 to 3.23) (table 4). Women who described living more than $30 \mathrm{~min}$ from a health centre or hospital offering obstetrical care or reporting no such facility nearby had a higher odds of MWH use than those residing within $30 \mathrm{~min}$ (OR: 2.37, 95\% CI 1.80 to 3.13) (table 4). Households with more wealth exhibited statistically significantly higher odds of MWH use compared with the poorest quintile.

Women's education levels, involvement in healthcare-related decision-making and community levels of institutional births were not significantly associated with MWH use in this sample.

\section{DISCUSSION}

In this study we found that the majority of women in our study were aware of the existence of MWHs but a very small proportion reported ever actually having used the service. A cross-sectional study conducted in 2014 in Eastern Gurage Zone, Ethiopia, reported just 7\% of women interviewed being aware of MWH services compared with $71 \%$ in our study. ${ }^{13}$ The formalisation of the national MWH guidelines in $2015^{4}$ and clarification of roles of various levels of government as well as HEWs in promoting $\mathrm{MWH}$ use may have influenced community awareness about the MWHs.

Most women accessed MWHs through referrals from health extension workers or health workers during antenatal care and generally stayed at MWHs for less than 24 hours before delivering their baby. The relatively short duration of stay suggests that many users are women who may be presenting with false or very early labour and are accommodated temporarily at the MWH; this may be due to the fact that they are not being referred to MWHs 1 to 2 weeks prior to delivery as recommended. ${ }^{4}$ Alternatively, while institutional births are valued by the population, MWHs may not necessarily be viewed as a service that facilitates access to obstetrical services by offering women the opportunity to be closer skilled birth attendants prior to delivery. Indeed, while most women were aware of MWH services, very few women who reported practicing birth preparedness considered MWHs as part 
Table 4 Results from multivariable random effects logistic regression analysis of MWH use among women in Jimma Zone, Ethiopia $(n=3782,99.9 \%)$

OR

$(95 \% \mathrm{Cl})$

P values

\section{Individual level}

Education

\begin{tabular}{|c|c|c|}
\hline No formal schooling & 1 & \\
\hline Some formal schooling & 1.08 (0.82 to 1.43$)$ & 0.5777 \\
\hline \multicolumn{3}{|l|}{ Occupation } \\
\hline Farmer/trader/other & 1 & \\
\hline Housewife & 1.74 (1.20 to 2.52$)$ & 0.003 \\
\hline \multicolumn{3}{|l|}{ Household level } \\
\hline \multicolumn{3}{|l|}{ Household wealth } \\
\hline Poorest & 1 & \\
\hline Second quintile & 1.85 (1.08 to 3.17$)$ & 0.026 \\
\hline Third quintile & 2.39 (1.42 to 4.03$)$ & 0.001 \\
\hline Fourth quintile & 3.20 (1.93 to 5.33$)$ & $<0.001$ \\
\hline Least poor & 2.39 (1.40 to 4.09$)$ & 0.001 \\
\hline \multicolumn{3}{|l|}{ Healthcare decision-making } \\
\hline Never involved & 1 & \\
\hline Sometimes involved & 0.86 (0.62 to 1.20$)$ & 0.378 \\
\hline Always involved & 0.59 (0.32 to 1.09$)$ & 0.094 \\
\hline \multicolumn{3}{|l|}{ Companion for facility visits } \\
\hline Absent & 1 & \\
\hline Present & 2.15 (1.44 to 3.23$)$ & $<0.001$ \\
\hline
\end{tabular}

Travel time to obstetrical

care facility

$\begin{array}{lll}\begin{array}{l}\leq 30 \text { min away } \\ >30 \text { min (none nearby) }\end{array} & 1 \\ \begin{array}{l}\text { Community level } \\ \text { Community birthing }\end{array} & 1.00(0.95 \text { to } 1.06) & 0.953 \\ \text { norms }\end{array}$

\section{Covariates}

District of residence

\begin{tabular}{lll} 
Gomma & 1 & \\
Kersa & $0.88(0.20$ to 3.98$)$ & 0.870 \\
Seka Chekorsa & $0.64(0.21$ to 1.94$)$ & 0.429 \\
\hline
\end{tabular}

$P$ values $<0.05$ considered statistically significant.

$\mathrm{MWH}$, maternity waiting home.

of their plans to ensure access to obstetrical care. This may partially explain why community norms around facility deliveries were not significantly associated with MWH use. Therefore, referral practices around, and promotion of, MWH use employed by HEWs and health workers in the area require investigation to ensure that the women who would benefit the most from this service are being reached. Qualitative reports of HEW perceptions influencing promotion of MWHs to the community has been reported in this area. ${ }^{32}$

Being a housewife, coming from relatively wealthier households, having companions to accompany women to health facilities and living more than $30 \mathrm{~min}$ from a health facility was associated with increased odds of MWH use. Despite MWH services being free, there may be financial and social costs associated with lodging there. Women from wealthier households are probably more likely to be able to afford to pay for transport, purchase food and accommodate accompanying relatives. Both direct and indirect costs have been described as barriers to $\mathrm{MWH}$ use in Ethiopia ${ }^{53}$ and other settings. ${ }^{34}$ Some studies have reported an inverse relationship between $\mathrm{MWH}$ use and household wealth in bivariable analysis ${ }^{35} 36$ and after adjusting for confounders. ${ }^{12}$ Various measures and cut-offs were used to determine relative wealth, including asking women to rate their household wealth in relation to their neighbours, ${ }^{35}$ which may partially account for the difference in findings. Our results suggest there may be a threshold wealth level after which households with more means may explore alternatives to MWHs such as paying for transport when women go into labour or going directly to a higher-level facility; this requires additional investigation. Extended absences from the home also result in losses of income that poor families can ill afford and can affect both intended and actual use. ${ }^{1337}$

Although most women in our study identified themselves as housewives without formal occupation commitments, close to $65 \%$ of these women said that they had worked in the past 12 months. Anecdotal evidence from the area suggests that in many cases women contribute to family farms and informal trade. However, compared with women with other occupations housewives were more likely to report having used MWH services. This suggests that women without formal work commitments may have more flexibility to stay at MWHs if they have the means and social support to facilitate this.

Social support has been described as an important facilitator of $\mathrm{MWH}$ use across several low- and middle-income countries. ${ }^{8}$ Women are frequently reluctant to stay at MWHs because it means leaving children unattended at home in the absence of help with childcare. ${ }^{13} 3839$ The presence of family to support and provide reassurance to women during birth is important and may even affect health and well-being of mother and baby. ${ }^{40}$ In fact, being surrounded by family and the comfort of home has been reported to be why some women prefer home births over facility deliveries. ${ }^{19} 4142$ This is important to consider as MWHs function as one of the entry-points to facility-based obstetrical care and likely share similar barriers to their use. Moreover, women often need to have someone help them prepare meals, fetch firewood and clean water while staying at MWHs. ${ }^{53}$ Although $71 \%$ of MWH users in our surveyed reported receiving a meal during their stay, this typically consists of a bowl of gruel usually prepared for women post-delivery. Moreover, reliance on community contributions to sustain the MWHs regularly results in 
food shortages according to anecdotal evidence generated during pre-intervention assessments. Therefore, women who have companions to accompany them at MWHs may not only have someone to facilitate their stay but may also benefit from emotional support prior to and during birth similar to the care that women receive at home, making MWH stay a more attractive option. Indeed, qualitative research from our setting ${ }^{32}$ and other areas in Ethiopia ${ }^{43}$ highlight the pivotal role of husbands and family support in enabling women's use of MWHs. Companions may also assist women receive the attention they need, but which they often do not get from health workers who have repeatedly been criticised for their neglect of MWH users. 114445

One of the functions of MWHs is to provide women who live at prohibitively large distances from health facilities the opportunity to access obstetrical services by accommodating them prior to delivery. ${ }^{6}$ It is therefore not surprising to find that women who report living within $30 \mathrm{~min}$ of a health facility are less inclined to use MWH services. In fact large distances between homes and health facilities are often part of MWH admission criteria. ${ }^{41135}$ Studies in Africa have reported distance from health facility affecting women's decisions to use MWH services ${ }^{44}$ as well as being associated with use. ${ }^{12}$

One of the strengths of this study was the use of models that accounted for clustering in the data, which if ignored underestimates variance while overestimating significance. ${ }^{46}$ Additionally, random selection of almost 4000 women from a representative community list should minimise the likelihood of selection bias. However, the cross-sectional nature of the analysis does not support causal inference limiting this to an exploratory exercise to identify factors that may influence MWH use. Also, the primary outcome relied on women's self-reported MWH use which may be subject to recall bias. However, this risk is likely low because staying at an MWH prior to delivery is expected to be a notable experience. Women's self-reported travel times estimates may not accurately reflect physical accessibility of MWHs; calculation of distances is recommended for future studies to assess the distance threshold for MWH use. Our results may have generalisability limited to districts with similar profiles to our given the purposive nature of district selection.

In conclusion, investigating what context-relevant factors influence the use of MWHs will help to better tailor care to suit women's needs. Our findings have important implications for achieving equity in access to maternal healthcare as poorer women, with little social support in the form of companions accompanying them for health facility visits, are likely to be among the more vulnerable groups. Further research into referral and promotion practices may also be warranted as results indicate suboptimal duration of stay at MWHs. When designing MWH programmes, it will be important to consider mobilising community support to overcome financial constraints and boost social networks.

\section{Author affiliations}

${ }^{1}$ School of Epidemiology and Public Health, University of Ottawa, Faculty of Medicine, Ottawa, Ontario, Canada

${ }^{2}$ Department of Health, Behaviour and Society, Jimma University, Jimma, Ethiopia ${ }^{3}$ Department of Population and Family Health, Jimma University, Jimma, Ethiopia ${ }^{4}$ Department of Health Economics, Management and Policy, Jimma University, Jimma, Ethiopia

${ }^{5}$ Faculty of Health Sciences, University of Ottawa, Ottawa, Ontario, Canada

${ }^{6}$ Jimma Zone Health Office, Jimma, Ethiopia

${ }^{7}$ Ottawa Hospital Research Institute, Ottawa, Ontario, Canada

Acknowledgements We would like to acknowledge the communities, survey staff and partners from the research areas who made this research possible. We thank Dr. Gail Webber, Dr. Vivian Welch, Dr. Donald Cole and Dr. Zohra Lassi for their comments on the manuscript.

Contributors JK and MK conceived and designed this study; LAG, MAW, SM, KHB, $G B, R L$ and MK designed the trial in which this study is nested. LAG, YA, GK, SM, $\mathrm{AM}, \mathrm{SA}$ and GB led data collection. JK, MK and MT conducted data analysis and interpretation. JK wrote up the manuscript. JK, MK, MT, LAG, MAW, SM, KHB, GB, RL, YA, GK, AM, SA and NB contributed to data interpretation, critically reviewed the manuscript and provided final approval.

Funding This work was carried out with the aid of a grant from the Innovating for Maternal and Child Health in Africa initiative - a partnership of Global Affairs Canada (GAC), the Canadian Institutes of Health Research (CIHR) and Canada's International Development Research Centre (IDRC).

Competing interests None declared.

Patient consent for publication Not required.

Ethics approval Ethical approval was obtained from the University of Ottawa Health Sciences and Science Research Ethics Board (File No: H10-15-25B) and the Jimma University College of Health Sciences Institutional Review Board (Ref No: RPGE/449/2016). Verbal informed consent for data collection was obtained from eligible women willing to participate in interviews. Trained research assistants read out the contents of the consent forms outlining the trial objectives, institutions and investigators involved and describing what was expected of women as well as associated risks and benefits. This was done in a local language of women's choice (Amharic or Afaan Oromo). Women were also explained their rights as participants and their questions answered prior to enrolment.

Provenance and peer review Not commissioned; externally peer reviewed.

Data availability statement Data are available upon reasonable request.

Open access This is an open access article distributed in accordance with the Creative Commons Attribution Non Commercial (CC BY-NC 4.0) license, which permits others to distribute, remix, adapt, build upon this work non-commercially, and license their derivative works on different terms, provided the original work is properly cited, appropriate credit is given, any changes made indicated, and the use is non-commercial. See: http://creativecommons.org/licenses/by-nc/4.0/.

\section{REFERENCES}

1. World Health Organization. World health statistics 2010.

2. Central Statistical Agency, DHS Program ICF. Ethiopia demographic and health survey 2016: key indicators report. Addis Ababa and Rockville, Maryland, 2016.

3. Ethiopian Federal Ministry of Health. Health sector development program IV: 2010/11 -2014/15 2010.

4. Ministry of Health Ethiopia.. Guideline for the establishment of standardized maternity waiting homes at health centres/facilities. Addis Ababa, 2015.

5. Gaym A, Pearson L, KWW S. Maternity waiting homes in Ethiopiathree decades experience. Ethiop Med J 2012;50:209-19.

6. World Health Organization. Maternity waiting homes: a review of experiences 1996.

7. van Lonkhuijzen L, Stekelenburg J, van Roosmalen J, et al. Maternity waiting facilities for improving maternal and neonatal outcome in low-resource countries. Cochrane Database Syst Rev 2012;4.

8. Penn-Kekana L, Pereira S, Hussein J, et al. Understanding the implementation of maternity waiting homes in low- and middleincome countries: a qualitative thematic synthesis. BMC Pregnancy Childbirth 2017;17:1-12. 
9. Scott NA, Vian T, Kaiser JL, et al. Listening to the community: using formative research to strengthen maternity waiting homes in Zambia. PLoS One 2018;13:e0194535.

10. Mclntosh N, Gruits P, Oppel E, et al. Built spaces and features associated with user satisfaction in maternity waiting homes in Malawi. Midwifery 2018;62:96-103.

11. Mramba L, Nassir FA, Ondieki C, et al. Reasons for low utilization of a maternity waiting home in rural Kenya. Int J Gynaecol Obstet 2010;108:152-3.

12. Fogliati P, Straneo M, Mangi S, et al. A new use for an old tool: maternity waiting homes to improve equity in rural childbirth care. results from a cross-sectional hospital and community survey in Tanzania. Health Policy Plan 2017;32:1354-60.

13. Vermeiden T, Braat F, Medhin G, et al. Factors associated with intended use of a maternity waiting home in southern Ethiopia: a community-based cross-sectional study. BMC Pregnancy Childbirth 2018;18:1-9.

14. Lori JR, Boyd CJ, Munro-Kramer ML, et al. Characteristics of maternity waiting homes and the women who use them: findings from a baseline cross-sectional household survey among SMGLsupported districts in Zambia. PLoS One 2018;13:e0209815.

15. Tarekegn SM, Lieberman LS, Giedraitis V. Determinants of maternal health service utilization in Ethiopia: analysis of the 2011 Ethiopian demographic and health survey. BMC Pregnancy Childbirth 2014;14.

16. Mohan D, Gupta S, LeFevre A, et al. Determinants of postnatal care use at health facilities in rural Tanzania: multilevel analysis of a household survey. BMC Pregnancy Childbirth 2015;15.

17. Say L, Raine R. A systematic review of inequalities in the use of maternal health care in developing countries: examining the scale of the problem and the importance of context. Bull World Health Organ 2007:85:812-9.

18. Mekonnen ZA, Lerebo WT, Gebrehiwot TG, et al. Multilevel analysis of individual and community level factors associated with institutional delivery in Ethiopia. BMC Res Notes 2015;8.

19. Hailu $D$, Berhe $H$. Determinants of institutional childbirth service utilisation among women of childbearing age in urban and rural areas of Tsegedie district, Ethiopia. Midwifery 2014;30:1109-17.

20. Gulliford M, Figueroa-Munoz J, Morgan M, et al. What does 'access to health care' mean? J Health Serv Res Policy 2002;7:186-8.

21. Braveman P, Gottlieb L. The social determinants of health: it's time to consider the causes of the causes. Public Health Rep 2014;129(1_ suppl2):19-31.

22. Temmerman M, Khosla R, Laski Z, et al. Women and Health Working Group for the Global Strategy for Women's C and AH. Women's health priorities and interventions. BMJ 2015;351.

23. Oromiya Bureau of Finance and Economic Development. Oromiya Housing \& Population Census, 2015. Available: http://www. oromiabofed.gov.et/images/stories/rstatistics/2007_oromia_housing Population_census.pdf [Accessed 24 Jul 2017].

24. Ethiopian Public Health Institute,. Federal Ministry of health Ethiopia, Columbia University. Ethiopian emergency obstetric and newborn care (EmONC) assessment 20162017.

25. Maternal Health Task Force. Health Extension Workers in Ethiopia. Delivering community-based antenatal and postnatal care 2014.

26. Caglia J, Kearns A, Langer A. Health extension workers in Ethiopia. delivering community-based antenatal and postnatal care 2014

27. Thaddeus S, Maine D. Too far to walk: maternal mortality in context. Soc Sci Med 1994;38:1091-110.

28. National Library of Medicine (US). An implementation study of interventions to promote safe motherhood in Jimma zone Ethiopia. Bethesda: National Library of Medicine (US), 2017.
29. Vyas S, Kumaranayake L. Constructing socio-economic status indices: how to use principal components analysis. Health Policy Plan 2006;21:459-68.

30. Stephenson R, Baschieri A, Clements S, et al. Contextual influences on the use of health facilities for childbirth in Africa. Am J Public Health 2006;96:84-93.

31. Donner A, Klar N. Design and analysis of cluster randomization trials in health research. Wiley, 2000.

32. Bergen N, Abebe L, Asfaw S, et al. Maternity waiting areas - serving all women? barriers and enablers of an equity-oriented maternal health intervention in Jimma zone, Ethiopia. Glob Public Health 2019;50:1-15.

33. Kelly J, Kohls E, Poovan P, et al. The role of a maternity waiting area (MWA) in reducing maternal mortality and stillbirths in high-risk women in rural Ethiopia. BJOG 2010;117:1377-83.

34. Ruiz MJ, van Dijk MG, Berdichevsky K, et al. Barriers to the use of maternity waiting homes in Indigenous regions of Guatemala: a study of users' and community members' perceptions. Cult Health Sex 2013;15:205-18.

35. Braat F, Vermeiden T, Getnet $G$, et al. Comparison of pregnancy outcomes between maternity waiting home users and non-users at hospitals with and without a maternity waiting home: retrospective cohort study. Int Health 2018;10:47-53.

36. Singh K, Speizer I, Kim ET, et al. Reaching vulnerable women through maternity waiting homes in Malawi. Int J Gynecol Obstet 2017;136:91-7.

37. Wilson JB, Collison AH, Richardson D, et al. The maternity waiting home concept: the Nsawam, Ghana experience. The Accra PMM team. Int J Gynaecol Obstet 1997;59:S165-72.

38. Sialubanje C, Massar K, Kirch EM, et al. Husbands' experiences and perceptions regarding the use of maternity waiting homes in rural Zambia. Int J Gynaecol Obstet 2016;133:108-11.

39. Tiruneh GT, Taye BW, Karim AM, et al. Maternity waiting homes in Rural Health Centers of Ethiop: the situation, women's experiences and challenges. J Heal Dev 2016;30:19-28.

40. Bohren MA, Hofmeyr GJ, Sakala C, et al. Continuous support for women during childbirth. Cochrane Database Syst Rev $2017 ; 2014$

41. Sisay MM, Yirgu R, Gobezayehu AG, et al. A qualitative study of attitudes and values surrounding stillbirth and neonatal mortality among grandmothers, mothers, and unmarried girls in rural Amhara and Oromiya regions, Ethiopia: unheard souls in the backyard. J Midwifery Womens Health 2014;59:S110-17.

42. Jackson R. Waiting-to-see" if the baby will come: findings from a qualitative study in Kafa Zone, Ethiopia. Ethiop J Heal Dev 2013;27:118-23.

43. Vermeiden T, Schiffer R, Langhorst J, et al. Facilitators for maternity waiting home utilisation at Attat Hospital: a mixedmethods study based on 45 years of experience. Trop Med Int Health 2018;23:1332-41.

44. Sialubanje C, Massar K, van der Pijl MSG, et al. Improving access to skilled facility-based delivery services: Women's beliefs on facilitators and barriers to the utilisation of maternity waiting homes in rural Zambia. Reprod Health 2015;12.

45. Sundu S, Gonekani Mwale O, Chirwa E. Antenatal mothers' experience of staying in a maternity waiting home at Malamulo Mission Hospital in Thyolo District Malawi: a qualitative, exploratory study. Women's Heal Gynecol 2017;3.

46. Brown AW, Li P, Bohan Brown MM, et al. Best (but oft-forgotten) practices: designing, analyzing, and reporting cluster randomized controlled trials. Am J Clin Nutr 2015;102:241-8. 